\title{
Ginkgolic acid inhibits the growth of renal cell carcinoma cells via inactivation of the EGFR signaling pathway
}

\author{
$\mathrm{CHAO} \mathrm{ZHU}^{1 *}, \mathrm{NA} \mathrm{NA}^{2 *}$, HAIBO SHENG ${ }^{3 *}, \mathrm{BING} \mathrm{FENG}^{1}, \mathrm{HAO} \mathrm{WANG}^{1}$, \\ PING ZHU ${ }^{4}$, WEI ZHANG ${ }^{4}$, MEINA ZHANG ${ }^{4}$ and ZHEN DENG ${ }^{5}$ \\ ${ }^{1}$ Department of Nephrology, Changhai Hospital, Second Military Medical University, Shanghai 200433; \\ ${ }^{2}$ Department of Outpatients, 900th Hospital of The Joint Logistics Support Force (People's Liberation Army), \\ Fuzhou, Fujian 350000; ${ }^{3}$ Department of Urology, Airforce Medical Center (People's Liberation Army), Beijing 100142; \\ ${ }^{4}$ Department of Pathology, 971st Navy Hospital of PLA, Qingdao, Shandong 266071; ${ }^{5}$ Department of Urology, 900th \\ Hospital of The Joint Logistics Support Force (People's Liberation Army), Fuzhou, Fujian 350000, P.R. China
}

Received June 18, 2019; Accepted January 9, 2020

DOI: $10.3892 /$ etm.2020.8570

\begin{abstract}
Renal cell carcinoma (RCC) is one of the most common urological malignancies occurring in adult human kidneys worldwide. Recent research on antitumor drugs has focused on plant extracts, a class of compounds that play critical roles in cancer treatment. The present study aimed to investigate the potential antitumor effect of ginkgolic acid (GA) in RCC. Transwell invasion assay, cell counting kit-8 assay and flow cytometry were used to measure cell migration, cell viability and apoptosis, respectively. A network pharmacology approach was applied to identify pathway information, combining molecular docking techniques to screen for key target information. In the present study, GA inhibited the viability and proliferation of RCC cells (786-O and $\mathrm{A} 498$ ), both in vitro and in vivo, via $\mathrm{G}_{1}$ arrest. GA also reduced $\mathrm{RCC}$ cell invasion and migration. In addition, the epidermal growth factor receptor (EGFR) was identified as a critical target protein of GA, which significantly inactivated EGFR signaling in RCC $(\mathrm{P}<0.05)$. Collectively, the present study provided evidence that GA exerts its anticancer function by directly targeting the EGFR signaling pathway, revealing the potential of GA therapy for RCC.
\end{abstract}

Correspondence to: Dr Zhen Deng, Department of Urology, 900th Hospital of The Joint Logistics Support Force (People's Liberation Army), 156 North Xierhuan Road, Fuzhou, Fujian 350000, P.R. China E-mail: sljsvui42982@126.com

Dr Wei Zhang, Department of Pathology, 971st Navy Hospital of PLA, 22 Minjiang Road, Qingdao, Shandong 266071, P.R. China

E-mail: zhangwei401@outlook.com

${ }^{*}$ Contributed equally

Key words: ginkgolic acid, renal cell carcinoma, epidermal growth factor receptor, network pharmacology, traditional Chinese medicine

\section{Introduction}

Renal cell carcinoma ( $\mathrm{RCC}$ ), the most common urogenital neoplasm, accounts for $\sim 5 \%$ of human adult malignancies worldwide (1). It is estimated that 64,000 new cases and 14,000 deaths occurred as a result of RCC in the United States in 2017 (1). Additionally, the worldwide incidence and mortality rates of RCC are steadily increasing (1). To date, metastatic lesions are present in $\sim 30 \%$ of patients at initial presentation due to an absence of symptoms at the early stages (2). Despite advances in therapeutic approaches, the prognosis of patients with RCC remains poor and $<40 \%$ of patients survive $\geq 5$ years post diagnosis, as therapeutic options are limited (3). Moreover, $\mathrm{RCC}$ recurrence is primarily due to the lack of routine adjuvant therapy in the clinic, as RCC is both chemotherapy and radiotherapy resistant $(4,5)$. Therefore, it is necessary to screen new compounds and develop novel targeted therapies for RCC.

The leaves and seeds of Ginkgo biloba L., an ancient gymnosperm species, have a long history of use in traditional Chinese medicine $(6,7)$. GA, which is characterized by a mixture of components containing 13-19 side chain carbon atoms at site 6 and 0-3 side chain double bonds, can be extracted from ginkgo fruit, exotesta and leaves (8-10). GA has been reported to display a wide range of bioactive properties, including antimicrobial, antivirus and molluscicidal activities (11). Accumulating evidence has demonstrated that several monomer structures of GA (C13:0, C15:0 and C17:1) exert antitumor activity in a number of human malignancies, including hepatocellular carcinoma as well as colon, breast and lung cancer (12-15). However, to the best of our knowledge, no previous study has been conducted to investigate the pharmacological effect of GA in RCC.

Network pharmacology, a novel systems pharmacology model, was established to explore the therapeutic mechanism of individual drugs on the basis of pharmacokinetics synthesis screening, target identification and network analysis $(16,17)$. A network pharmacology-based approach has displayed potential for investigating the therapeutic mechanism of natural agents in a number of malignancies, including lung cancer, breast cancer and hepatocellular carcinoma $(18,19)$. 
The identification of the therapeutic mechanism of GA could facilitate more precise GA application in malignant cancer treatment. Therefore, the present study utilized a network pharmacology-based approach to explore the key target of GA. Subsequently, molecular docking, a theoretical simulation method, was used to analyze the interaction between molecules and to predict the binding site and affinity of GA to ensure the accuracy and effectiveness of the network analysis.

\section{Materials and methods}

Cell culture and chemicals. The human RCC cell lines 786-O and A498 were purchased from the Cell Bank of Type Culture Collection of the Chinese Academy of Sciences. Cells were grown in RPMI 1640 medium (Sigma-Aldrich; Merck KGaA) supplemented with $10 \%$ fetal bovine serum (HyClone; GE Healthcare Life Sciences) and $100 \mu \mathrm{g} / \mathrm{ml}$ penicillin/streptomycin at $37^{\circ} \mathrm{C}$ in a humidified incubator with $5 \% \mathrm{CO}_{2}$. GA (C17:1; $\mathrm{C}_{24} \mathrm{H}_{38} \mathrm{O}_{3}$; Tauto Biotech Co., Ltd.; Fig. 1A) was dissolved in DMSO (Sigma-Aldrich; Merck KGaA) to make a $20 \mathrm{mM}$ stock solution. For cell treatment, 10 and $20 \mu \mathrm{M} \mathrm{GA}$ (diluted in RPMI 1640 medium) were used.

Cell viability assay. 786-O and A498 cells were seeded at a density of $1 \times 10^{3}$ cells per well in 96 -well plates. After culture for $12 \mathrm{~h}$ at $37^{\circ} \mathrm{C}$, the medium was replaced with maintenance medium containing the desired concentrations (10 and $20 \mu \mathrm{M}$ ) of GA or DMSO. Cell viability was assessed after $72 \mathrm{~h}$ incubation at $37^{\circ} \mathrm{C}$ using an MTT assay kit (Nanjing KeyGen Biotech Co., Ltd.) according to the manufacturer's protocols. DMSO was used to dissolve formazan crystals and absorbance was measured in each well at $450 \mathrm{~nm}$ using a 318C microplate reader (Shanghai Peiou Analytical Instruments Co., Ltd.).

Transwell invasion assay. To determine c ell invasion, invasion assays were performed using 24-well Matrigel-coated invasion chambers ( $8-\mu \mathrm{m}$ pore size; Corning Inc.). RCC cells were pre-treated with GA for $24 \mathrm{~h}$, seeded into the upper chamber of the Transwell insert and incubated for $24 \mathrm{~h}$ at $37^{\circ} \mathrm{C}$. Subsequently, cells on the upper side of the membrane were wiped off and invading cells were fixed in $100 \%$ cold methanol at $4^{\circ} \mathrm{C}$ for $20 \mathrm{~min}$ and stained with $0.2 \%$ crystal violet at room temperature for $30 \mathrm{~min}$ (Sigma-Aldrich; Merck KGaA). The stained cells were quantified under a light microscope, from five randomly selected fields of view (magnification, $\mathrm{x} 400$ ).

Wound healing assay. RCC cells were pre-treated with 10 and $20 \mu \mathrm{M} \mathrm{GA}$ for $24 \mathrm{~h}$ at $37^{\circ} \mathrm{C}$ and allowed to grow to $90-95 \%$ confluence without serum. The cell monolayers were scratched with a sterile $200-\mu l$ pipette tip. Subsequently, the cells were washed with RPMI 1640 medium to remove cell debris and fresh cell culture medium (RPMI 1640 medium supplemented with $10 \%$ FBS) was added. Images of the scratches were obtained at 0 and $24 \mathrm{~h}$ using a light microscope (magnification, x200). Migratory ability was measured as the percentage of wound closure with the initial wound width defined as 1 .

Cell cycle and early apoptosis assay. Cell cycle distribution and apoptosis were analyzed using the Annexin V-FITC Apoptosis kit (Solarbio Life Sciences) according to the manufacturer's protocols. Briefly, RCC cells were cultured in RPMI 1640 medium in 6-well plates at a density of $1 \times 10^{6}$ cells for $12 \mathrm{~h}$ at $37^{\circ} \mathrm{C}$. Then, the medium was replaced with RPMI 1640 medium containing $20 \mu \mathrm{M}$ GA. Cells were stained with Annexin V-FITC and propidium iodide buffer at room temperature for $15 \mathrm{~min}$ followed by the addition of Annexin V binding buffer. Cell cycle and apoptosis assays were performed on a BD Accuri C6 (BD Biosciences) flow cytometer and BD Accuri C6 software Version 1.0 (Becton, Dickinson and Company) was used to analyze the data.

Xenograft implantation. Animal experiments were approved by The Animal Care and Use Committee of the Second Military Medical University (approval no. NMU20181032). Animals had free access to autoclaved chow diet and water in a pathogen-free state, at $22 \pm 1^{\circ} \mathrm{C}$ with $45 \pm 10 \%$ humidity and 12-h light/dark cycles. The health and behaviour of the mice were monitored every $12 \mathrm{~h}$. Moribund mice (exhibiting anorexia, immobility or an unkempt coat) would be euthanized by $\mathrm{CO}_{2}$ at the rate of $3.5 \mathrm{1} / \mathrm{min}$ displacing $20 \%$ of the cage volume per minute. Death was verified by monitoring cessation of breathing. To detect the effect of GA on tumorigenicity in nude mice, 6-8-week-old male BALB/c mice ( $\mathrm{n}=10$; weight, 20-30 g; Second Military Medical University) were injected subcutaneously with $786-\mathrm{O}$ or A498 cells $\left(1 \times 10^{7}\right.$ dissolved in PBS per site; one tumor burden per mouse) on the right flank. Mice were randomly divided into two groups ( $\mathrm{n}=5$ per group) that either received an intragastric administration of GA $(10 \mathrm{mg} / \mathrm{kg})$ or $0.9 \%$ saline twice per week (13). At 6 weeks after GA injection, mice were euthanized by decapitation. The tumor volumes and weight were measured. Prior to 6 weeks after GA injection, no mice were euthanized or found dead.

Protein-protein interaction (PPI) network construction and analysis. The Online Mendelian Inheritance in Man (OMIM) Database (version 1.0; www.ncbi.nlm.nih.gov/omim), from which the original data used in the present study was obtained, is a central-level database covering relevant information and literature on human genetic diseases and gene loci. Data were input into the Search Tool for the Retrieval of Interacting Genes/Proteins (version 11.0; string-db.org) database for further network construction. The obtained PPI networks were then visualized using Cytoscape software (version 3.6.1; https://cytoscape.org). Topology analysis (CentiScaPe plug-in; version 2.2; http://apps. cytoscape.org/download/stats/centiscape/) was used to identify key targets in the network. Degrees of betweenness were assessed using the key hubs of centrality, namely betweenness (the number between nodes) and closeness (the distance between nodes).

Molecular docking. The docking between GA and key targets of RCC was implemented using Sybyl X software (version 2.1.1; https://en.freedownloadmanager.org/Windows-PC/SYBYL-X. html). The conformation of GA was downloaded from the Traditional Chinese Medicine Systems Pharmacology Database (version 1.0; https://tcmspw.com/tcmsp.php). The mol2 format file was further transformed and extracted by Openbabel software (release date, 2017-02-22; https://sourceforge.net/projects/openbabel/). The X-ray crystal structures of key targets were obtained from the RCSB Protein Data Bank (version 1.0; www.rcsb.org). Prior to docking, targets were structurally 
A<smiles>CCCCCCCCCCCCc1cccc(O)c1C(=O)O</smiles>

C

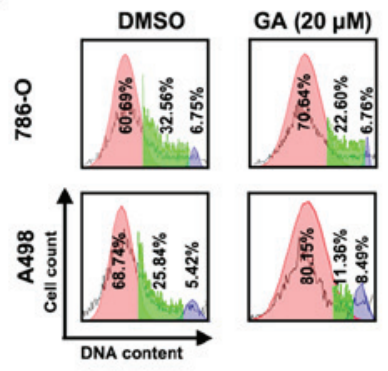

D

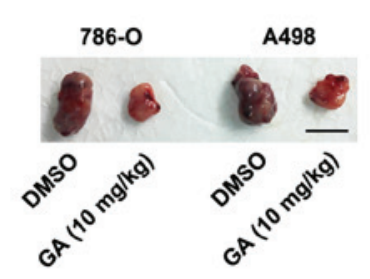

B

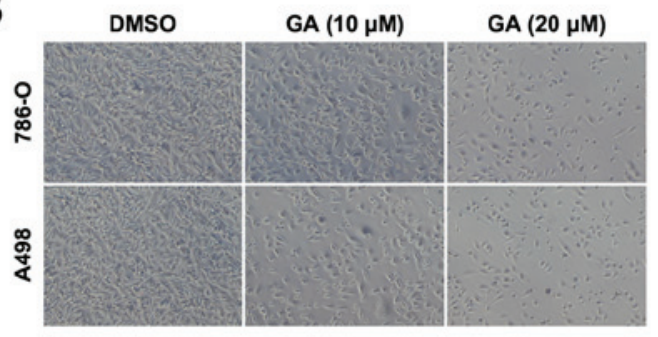

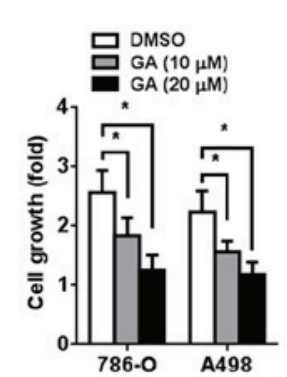

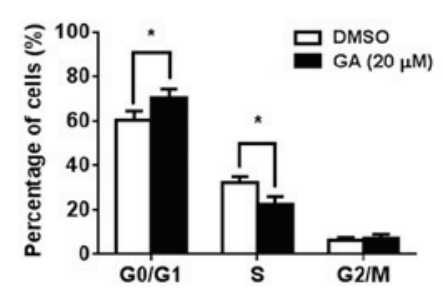

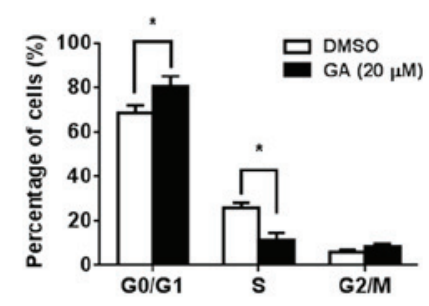

Figure 1. Effect of GA on RCC cell proliferation. 786-O and A498 cells were pre-treated with or without 10 or $20 \mu \mathrm{M}$ GA, as indicated. (A) Chemical structure of GA (C17:1; $\mathrm{C}_{24} \mathrm{H}_{38} \mathrm{O}_{3}$ ). (B) Representative images and quantification of cell viability (magnification, x200). Cell viability analysis was performed $72 \mathrm{~h}$ after

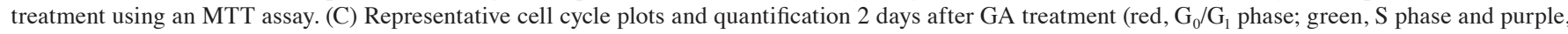
G0/M phase). Assessment of cell phase percentage was conducted using flow cytometry. (D) Representative images and quantification of subcutaneous xenograft tumors derived from mice in the GA and DMSO groups. Scale bar, $1 \mathrm{~cm}$. Tumor weight was measured 6 weeks after injection. (E) Representative image and quantification of immunohistochemical staining for Ki-67 (magnification, x200). n=5. * P<0.05. GA, ginkgolic acid; RCC, renal cell carcinoma. optimized by adding hydrogen atoms and removing water molecules, and the representative protein activity docking pockets were subsequently generated. Molecular docking was implemented based on the Docking Suite module (release date, 2013-04-08; https://sourceforge.net/projects/wpfdocking/) and hydrogen bond stability and domain structure similarity were used to evaluate the reliability of results. The criteria of binding scoring: 0-3, Poor; 4-6, moderate; and 7-10, good.

Immunohistochemistry and immunoblotting assay. Cells were pre-treated with $10 \mathrm{ng} / \mathrm{ml}$ epidermal growth factor (EGF; PeproTech, Inc.) for $12 \mathrm{~h}$ at $37^{\circ} \mathrm{C}$. Immunohistochemical assays of xenografts were conducted using Ki-67 (cat. no. ab15580; 1:50; Abcam) and EGF receptor (EGFR; cat. no. ab52894; 1:50; Abcam) monoclonal antibodies, as previously described (20). The expression level was analyzed from images obtained using a light microscope (magnification, x200) from five random fields of view. Immunoblot assays were performed as previously described (20). Primary antibodies included those targeted against phosphorylated (p)-EGFR (cat. no. 4370; 1:1,000; Cell Signaling Technology, Inc.), EGFR (cat. no. 2085; 1:1,000; Cell Signaling Technology, Inc.), p-Akt (Ser473; cat. no. 4060; 1:1,000; Cell Signaling Technology, Inc.), Akt (cat. no. 4691; 1:1,000; Cell Signaling Technology, Inc.), p-ERK
(Thr202/Tyr204; cat. no. 4370; 1:1,000; Cell Signaling Technology, Inc.) and ERK (cat. no. 4370; 1:1,000; Cell Signaling Technology, Inc.). Horseradish peroxidase-conjugated secondary antibody (1:2,000; cat. no. ab6112; Abcam) was used. $\beta$-actin antibody (cat. no. ab8226; 1:5,000; Abcam) was used as a control. Relative protein expression and staining intensity was calculated based on the densitometric analysis by Image Lab software Version 3.0 (Bio-Rad Laboratories, Inc.).

Statistical analysis. All data are presented as the mean \pm SD. SPSS software (version 18.0; SPSS Inc.) was used for statistical analysis. The statistical significance between two groups was analyzed using an unpaired Student's t-test. One-way ANOVA followed by a Dunnett's post hoc test was performed to compare data among $\geq 3$ groups. $\mathrm{P}<0.05$ was considered to indicate a statistically significant difference.

\section{Results}

GA inhibits RCC cell proliferation in vitro and in vivo. To investigate the role of GA in RCC, human RCC cells (786-O and A498) were incubated with different concentrations of GA. An MTT assay was performed $72 \mathrm{~h}$ after treatment and a dose-dependent decrease in cell viability was observed 
A
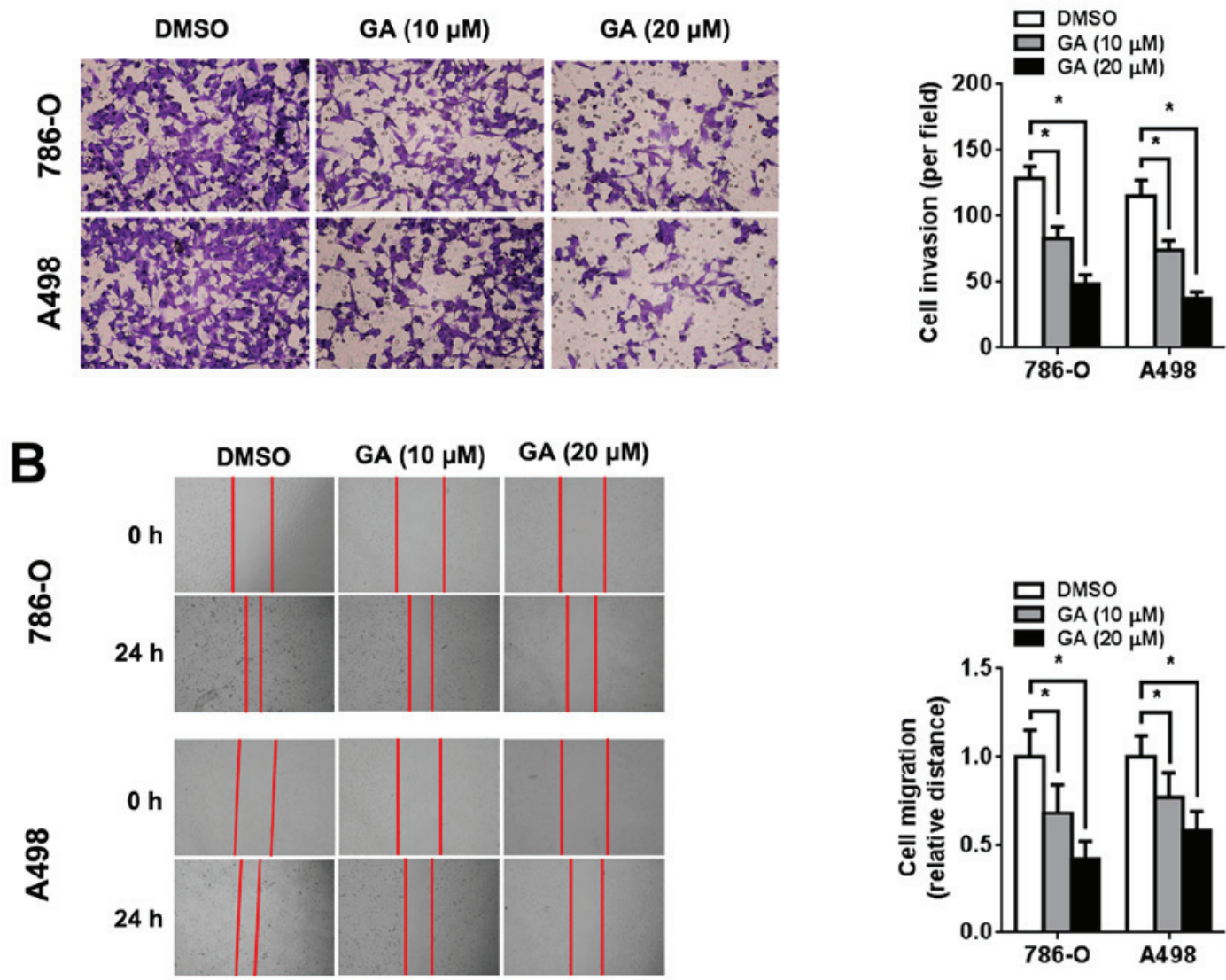

Figure 2. GA inhibits the migration and invasion ability of RCC cells. (A) Matrigel-coated invasion chamber following treatment with DMSO or GA (10 or $20 \mu \mathrm{M}$ ) and quantification of the number of invading cells in each chamber (magnification, $\mathrm{x} 400$ ). (B) Wound healing assays were performed in RCC cells treated with DMSO or GA (10 or $20 \mu \mathrm{M})$. Representative images were obtained at 0 and 24 h (magnification, x 100). Quantification of migratory distance. Scale bar, $100 \mu \mathrm{m} . \mathrm{n}=5$. ${ }^{*} \mathrm{P}<0.05$, as indicated. GA, ginkgolic acid; RCC, renal cell carcinoma.

(Fig. 1B). In addition, GA increased the proportion of cells in the $\mathrm{G}_{0} / \mathrm{G}_{1}$ phase and decreased the proportion of cells in the $\mathrm{S}$ phase (Fig. 1C). However, GA treatment did not significantly affect RCC cell apoptosis (Fig. S1). Based on in vitro data, xenograft implantation in $\mathrm{BALB} / \mathrm{c}$ nude mice was performed to clarify the effect of GA on RCC in vivo. RCC cell suspensions $\left(1 \times 10^{7}\right)$ were subcutaneously injected into nude mice. The tumor volumes and weights of the group treated with GA were significantly lower compared with those of the group treated with $0.9 \%$ saline $(\mathrm{P}<0.05$; Figs. 1D and $\mathrm{S} 2 \mathrm{~A}$ ). In the present study, the maximum diameter of a single tumor was $1.8 \mathrm{~cm}$. However, no significant difference in body weight loss was observed between the two groups (Fig. S2C). Additionally, immunohistochemical staining revealed that GA significantly reduced $\mathrm{Ki}-67$ expression in the xenograft $(\mathrm{P}<0.05$; Fig. 1E).

GA inhibits RCC cell invasion and migration. The effect of GA on the invasion and migration of RCC cells was evaluated using Transwell invasion and wound healing assays, respectively. Transwell invasion assays showed that GA reduced the number of invading RCC cells in a dose-dependent manner (Fig. 2A). Consistent with this result, wound healing assays also showed that GA inhibited RCC cell migration in a dose-dependent manner (Fig. 2B).
PPI network and topology analysis. The interaction network was constructed based on OMIM original data and is depicted in Fig. 3, and included 549 nodes and 11,836 edges. Larger areas and deeper colours represent higher node connectivity, which likely indicates greater importance of the node in the network. The results displayed the scale-free property of the network, meaning the number of nodes decreases as the number of edges in the network increases. Betweenness degree was used to distinguish these highly connected key nodes from other nodes in the network (Fig. 4). Finally, 15 key targets were selected: Tumor protein p53, 284 points; albumin, 267 points; AKT1, 251 points; vascular endothelial growth factor A, 243 points; insulin, 230 points; interleukin 6, 223 points; JUN, 215 points; tumor necrosis factor, 213 points; MYC, 211 points; phosphatidylinositol-4,5-bisphosphate 3-kinase catalytic subunit- $\alpha, 208$ points; EGFR, 198 points; mitogen-activated protein kinase 1, 186 points; transforming growth factor $\beta 1,185$ points; BCL2, 179 points; and STAT3, 173 points.

GA inactivates the EGFR pathway in RCC. Molecular docking, a tool for studying the interaction strength between molecules, was used to explore the accuracy and effectiveness of the PPI network. To assess the reliability of the aforementioned drug-target interactions and to further investigate binding mode and affinity, molecular docking models were 


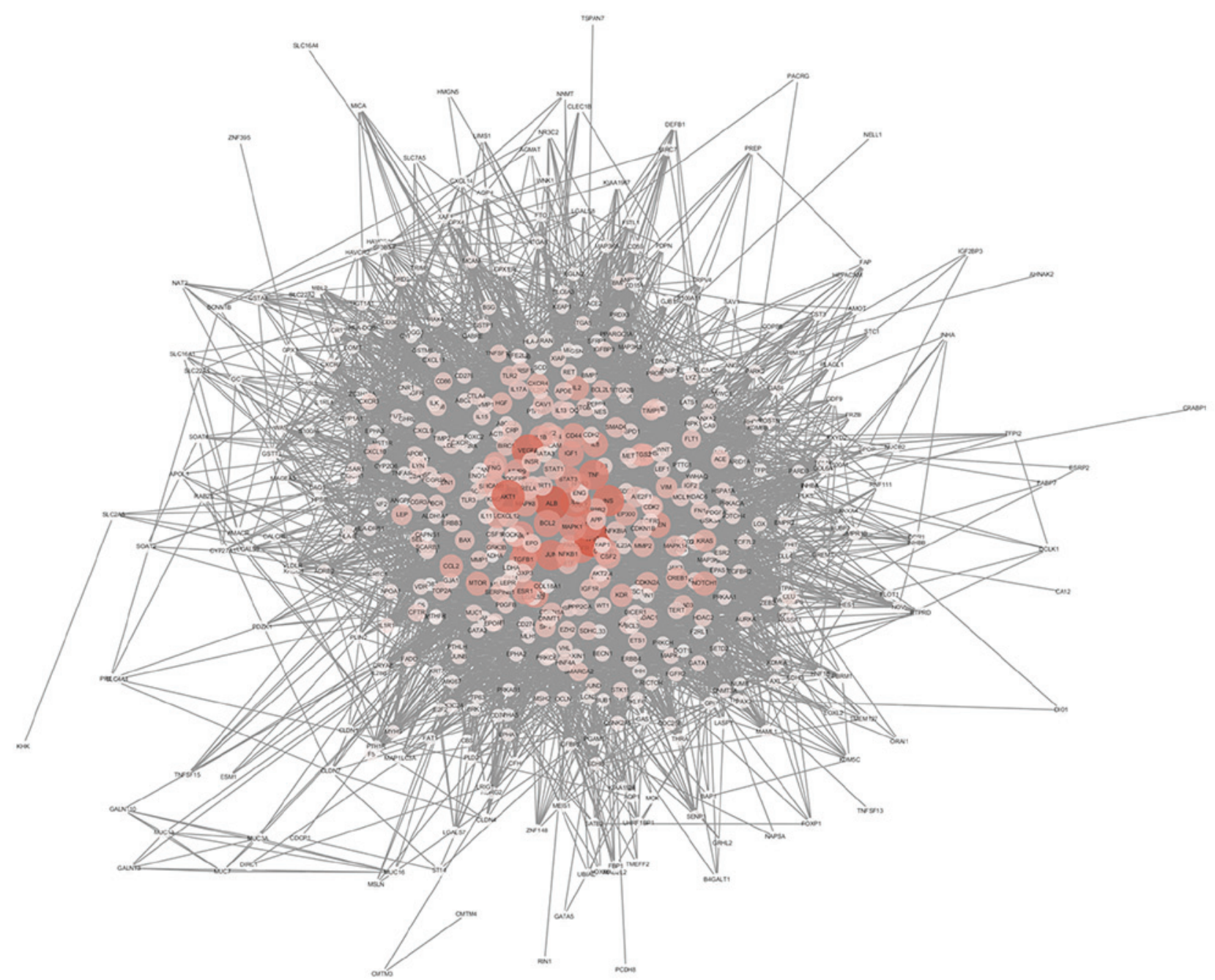

Figure 3. Protein-protein interaction network including 549 nodes and 11,836 edges. Larger areas and deeper colours represent higher node connectivity.

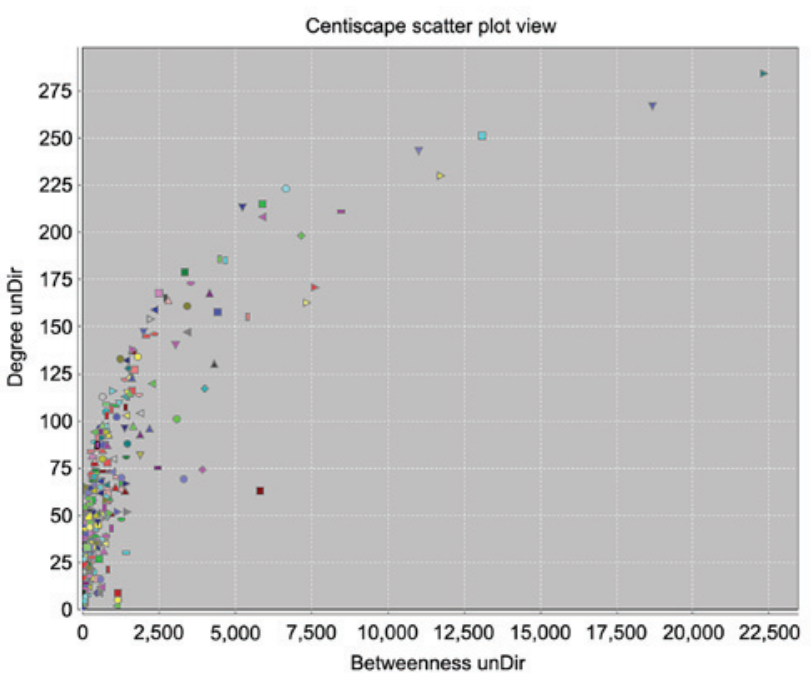

Figure 4. Topological analysis. The higher the degree of the node, the more important the node is in the network. unDir, undirected index.

constructed for GA and the 15 key targets. Analysis of the binding data indicated stable conformational binding and good scoring ( $>7$ points) of EGFR to GA (9.4558 points; Fig. 5A).
Immunohistochemical staining displayed lower EGFR expression in the xenograft after GA treatment compared to before treatment (Fig. 5B). The immunoblotting assay demonstrated that EGFR, p-Akt and p-Erk (downstream of the EGFR signaling pathway) were significantly downregulated after GA treatment in xenografts, as well as in vitro $(\mathrm{P}<0.05$; Fig. $5 \mathrm{C})$.

\section{Discussion}

Despite great advances in cancer therapy, major limitations still exist in the management of RCC (21). Moreover, patients with metastatic RCC have a short life expectancy (median overall survival, 22.5 months) (22). Extracts from natural plants are becoming an increasingly popular strategy to identify novel antitumor compounds $(23,24)$. Recently, several studies have reported that GA displays promising antitumor activities (12-15). Therefore, identification of the regulatory mechanism of GA in tumorigenesis would provide valuable insight for the treatment of malignancies. Collectively, the results of the present study indicated that GA suppressed the development of RCC. These results were consistent with previous studies demonstrating that GA plays an inhibitory biological role in cancer $(12-15,25)$. However, the biological effect of GA on RCC was observed at high concentrations of 
A
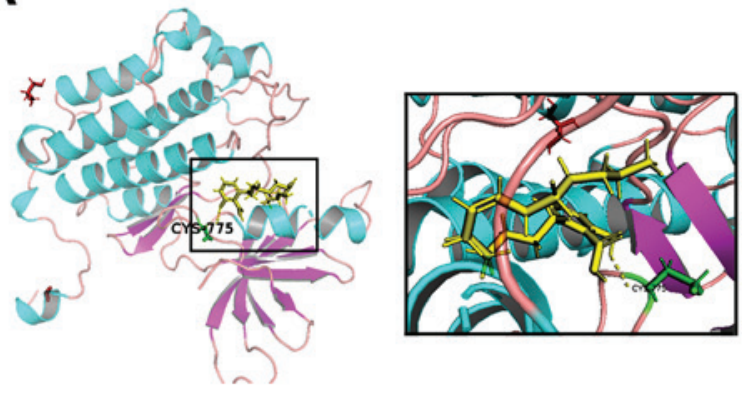

C
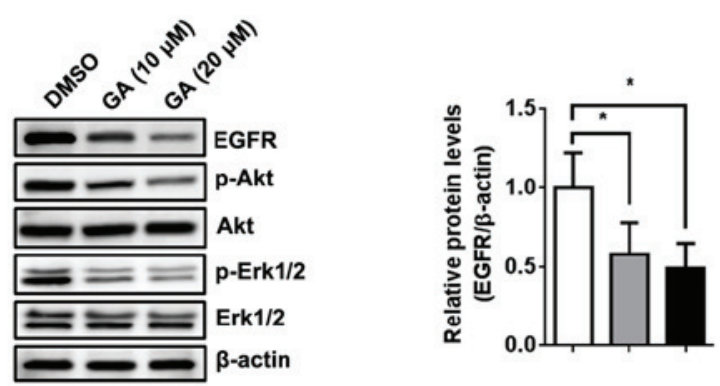

B

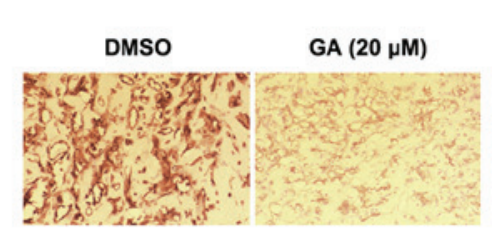

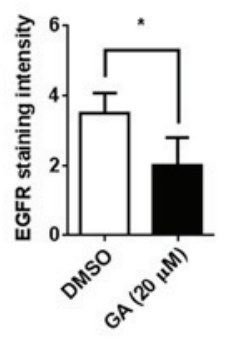
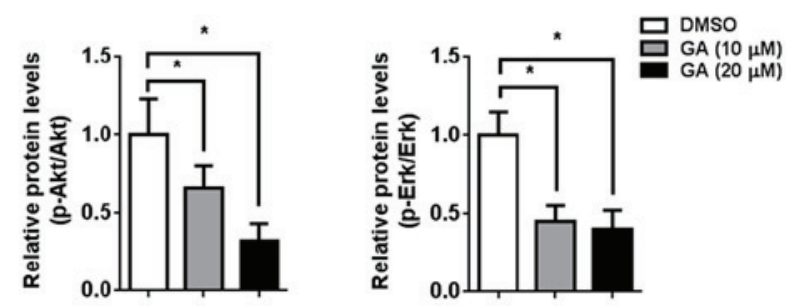

Figure 5. GA exerts its function via suppressing the EGFR pathway. (A) Binding interaction model of EGFR and GA. (B) Mice were injected subcutaneously with 786-O cells ( $1 \times 10^{7}$ cells) followed by intragastric administration of GA ( $\left.10 \mathrm{mg} / \mathrm{kg}\right)$ or $0.9 \%$ saline twice per week. Representative image and quantification of immunohistochemical staining for EGFR in the xenograft (magnification, x200). (C) $786-\mathrm{O}$ cells were pre-treated with $10 \mathrm{ng} / \mathrm{ml}$ EGF for $12 \mathrm{~h}$ at $37^{\circ} \mathrm{C}$ followed by DMSO or GA for $48 \mathrm{~h}$ at $37^{\circ} \mathrm{C}$. The expression of p-EGFR, EGFR, p-Akt, Akt, p-Erk1/2 and Erk1/2 was analyzed by immunoblotting. $\beta$-actin was used as an internal control. $\mathrm{n}=5$. * $\mathrm{P}<0.05$, as indicated. GA, ginkgolic acid; EGFR, epidermal growth factor receptor; EGF, epidermal growth factor; p, phosphorylated.

GA in vitro and it is uncertain whether this concentration would be possible in vivo. Therefore, further in vivo investigation (pharmacokinetics and toxicology analysis) is required.

GA suppresses tumor growth and invasion via various signaling pathways, including the hepatocyte growth factor/c-Met signaling pathway in hepatocellular carcinoma (12), the protein kinase AMP-activated catalytic subunit $\alpha 2$ signaling pathway in colon cancer (13), the NF- $\mathrm{B}$ signaling pathway in breast cancer (14) and the PI3K/Akt/mTOR signaling pathway in lung cancer (15). A number of studies have reported that, in addition to inducing cell cycle arrest, GA also increases apoptosis in colon cancer and hepatocellular carcinoma $(26,27)$. Therefore, it is difficult to clarify the antitumor mechanism of GA in RCC. Network pharmacology provides a strategy to investigate complex mechanisms of drug action and to identify potential drug targets (28). In a network pharmacology system, therapy response can be taken into account based on the robustness of complex disease networks in dealing with node attacks (node linking degree) due to inherent diversity and redundant compensation signaling pathways $(12,19)$. The result of network pharmacology is a highly resilient network system with topological interaction $(19,29)$. Therefore, computational prediction with a PPI network and topology analyses reveals the potential interactions among compounds and multiple signaling transduction molecules underlying a disease phenotype (30). According to the algorithm value, 15 key targets associated with RCC were identified in the current study. Furthermore, analysis of the molecular docking model demonstrated a stable conformational affinity between EGFR and GA. EGFR was validated as a direct target for GA both in vitro and in vivo. Furthermore, GA negatively modulated p-Akt and p-Erk expression via the EGFR/Akt/Erk signaling pathway in RCC cells. However, the mechanism of EGFR protein degradation (autophagy and ubiquitination) requires further investigation.

EGFR belongs to the ErbB family of receptor tyrosine kinases, which can be activated by several ligands, including EGF, transforming growth factor- $\alpha$, amphiregulin, heparin-binding EGF, $\beta$-cellulin and epiregulin (31-34). In humans, EGFR is upregulated and/or activated in various malignancies and suppression of EGFR activation is considered a valid strategy for tumor treatment $(34,35)$. Akt and Erk are downstream signaling molecules of EGFR, and the aberrant activation of either triggers a cascade of proliferative responses (36). Akt and Erk phosphorylation are increased when EGFR is activated in RCC $(37,38)$. Previous studies have provided direct evidence that the EGFR signaling pathway is highly activated in RCC progression and EGFR expression is associated with prognosis in patients with clear cell RCC (38-40). Furthermore, inactivation of the EGFR signaling pathway inhibited RCC cell migration and invasion in vitro (41). These data imply that activation of the EGFR signaling pathway may be an important event that occurs during RCC development. The present study demonstrated that GA, which acts as a suppressor of EGFR, exhibited a biological effect in RCC cells via the EGFR/Akt/Erk signaling pathway.

The present study investigated the molecular mechanism by which GA exerts its negative effects on proliferation, invasion and migration in human RCC cells. GA significantly inhibited 
the EGFR signaling pathway by directly binding to EGFR. The downstream targets of EGFR, including p-Akt and p-Erk, were also downregulated following GA treatment. EGFR, as a novel target of GA, may be a promising therapeutic agent for human RCC.

\section{Acknowledgements}

Not applicable.

\section{Funding}

The present study was supported by The Medical Research Project of Hongkou District of Shanghai (grant no. 1702-11) and The Natural Science Foundation of Fujian Province (grant no. 2016J05196).

\section{Availability of data and materials}

The datasets used and/or analyzed during the present study are available from the corresponding author on reasonable request.

\section{Authors' contributions}

$\mathrm{ZD}$ and $\mathrm{BF}$ contributed to the conception and design of the study. CZ, NN, HW and MZ performed the experiments. PZ and WZ analyzed the data. HS participated in the design of the study. All authors read and approved the final version of the manuscript.

\section{Ethics approval and consent to participate}

The present study was approved by The Ethics Committee of the Second Military Medical University (approval no. NMU20181032; Shanghai, China).

\section{Patient consent for publication}

Not applicable.

\section{Competing interests}

The authors declare that they have no competing interests.

\section{References}

1. Siegel RL, Miller KD and Jemal A: Cancer statistics, 2017. CA Cancer J Clin 67: 7-30, 2017.

2. Cindolo L, Patard JJ, Chiodini P, Schips L, Ficarra V, Tostain J, de La Taille A, Altieri V, Lobel B, Zigeuner RE, et al: Comparison of predictive accuracy of four prognostic models for nonmetastatic renal cell carcinoma after nephrectomy: A multicenter European study. Cancer 104: 1362-1371, 2005 .

3. Patil S, Ishill N, Deluca J and Motzer RJ: Stage migration and increasing proportion of favorable-prognosis metastatic renal cell carcinoma patients: Implications for clinical trial design and interpretation. Cancer 116: 347-354, 2010.

4. Redova M, Svoboda M and Slaby O: MicroRNAs and their target gene networks in renal cell carcinoma. Biochem Biophys Res Commun 405: 153-156, 2011.

5. Mangolini A, Bonon A, Volinia S, Lanza G, Gambari R, Pinton P, Russo GR, Del Senno L, Dell'Atti L and Aguiari G: Differential expression of microRNA501-5p affects the aggressiveness of clear cell renal carcinoma. FEBS Open Bio 4: 952-965, 2014.
6. van Beek TA and Wintermans MS: Preparative isolation and dual column high-performance liquid chromatography of ginkgolic acids from Ginkgo biloba. J Chromatogr A 930: 109-117, 2001.

7. Major RT: The ginkgo, the most ancient living tree. The resistance of Ginkgo biloba L. to pests accounts in part for the longevity of this species. Science 157: 1270-1273, 1967.

8. Siegers CP: Cytotoxicity of alkylphenols from Ginkgo biloba. Phytomedicine 6: 281-283, 1999.

9. Hecker H, Johannisson R, Koch E and Siegers CP: In vitro evaluation of the cytotoxic potential of alkylphenols from Ginkgo biloba L. Toxicology 177: 167-177, 2002.

10. Zhou C, Li X, Du W, Feng Y, Kong X, Li Y, Xiao L and Zhang P: Antitumor effects of ginkgolic acid in human cancer cell occur via cell cycle arrest and decrease the Bcl-2/Bax ratio to induce apoptosis. Chemotherapy 56: 393-402, 2010.

11. Lü JM, Yan S, Jamaluddin S, Weakley SM, Liang Z, Siwak EB, Yao Q and Chen C: Ginkgolic acid inhibits HIV protease activity and HIV infection in vitro. Med Sci Monit 18: BR293-BR298, 2012.

12. Li H, Meng X, Zhang D, Xu X, Li S and Li Y: Ginkgolic acid suppresses the invasion of HepG2 cells via downregulation of HGF/cMet signaling. Oncol Rep 41: 369-376, 2019.

13. Qiao L, Zheng J, Jin X, Wei G, Wang G, Sun X and Li X: Ginkgolic acid inhibits the invasiveness of colon cancer cells through AMPK activation. Oncol Lett 14: 5831-5838, 2017.

14. Hamdoun $\mathrm{S}$ and Efferth T: Ginkgolic acids inhibit migration in breast cancer cells by inhibition of NEMO sumoylation and NF- $\kappa$ B activity. Oncotarget 8: 35103-35115, 2017.

15. Baek SH, Ko JH, Lee JH, Kim C, Lee H, Nam D, Lee J, Lee SG, Yang WM, Um JY, et al: Ginkgolic acid inhibits invasion and migration and TGF- $\beta$-induced EMT of lung cancer cells through PI3K/Akt/mTOR inactivation. J Cell Physiol 232: 346-354, 2017.

16. Ye HZ, Zheng CS, Xu XJ, Wu MX and Liu XX: Potential synergistic and multitarget effect of herbal pair Chuanxiong Rhizome-Paeonia Albifora Pall on osteoarthritis disease: A computational pharmacology approach. Chin J Integr Med 17: 698-703, 2011.

17. Xenarios I, Salwínski L, Duan XJ, Higney P, Kim SM and Eisenberg D: DIP, the database of interacting proteins: A research tool for studying cellular networks of protein interactions. Nucleic Acids Res 30: 303-305, 2002.

18. Xu R and Wunsch DC II: Clustering algorithms in biomedical research: A review. IEEE Rev Biomed Eng 3: 120-154, 2010.

19. Ramadan E, Naef A and Ahmed M: Protein complexes predictions within protein interaction networks using genetic algorithms. BMC Bioinformatics 17 (Suppl 7): S269, 2016.

20. Wang D, Zhu C, Zhang Y, Zheng Y, Ma F, Su L and Shao G: MicroRNA-30e-3p inhibits cell invasion and migration in clear cell renal cell carcinoma by targeting Snail1. Oncol Lett 13: 2053-2058, 2017.

21. Renal cell cancer treatment (PDQ $(\mathrm{R}))$ : Patient version, in PDQ cancer information summaries. 2002: Bethesda (MD).

22. Shingarev R and Jaimes EA: Renal cell carcinoma: New insights and challenges for a clinician scientist. Am J Physiol Renal Physiol 313: F145-F154, 2017.

23. Wang C, Ren Q, Chen XT, Song ZQ, Ning ZC, Gan JH, Ma XL, Liang DR, Guan DG, Liu ZL and Lu AP: System pharmacology-based strategy to decode the synergistic mechanism of Zhi-zhu Wan for functional dyspepsia. Front Pharmacol 9: 841, 2018.

24. Zhang J, Li Y, Chen X, Pan Y, Zhang S and Wang Y: Systems pharmacology dissection of multi-scale mechanisms of action for herbal medicines in stroke treatment and prevention. PLoS One 9: e102506, 2014.

25. Ma J, Duan W, Han S, Lei J, Xu Q, Chen X, Jiang Z, Nan L, Li J, Chen K, et al: Ginkgolic acid suppresses the development of pancreatic cancer by inhibiting pathways driving lipogenesis. Oncotarget 6: 20993-21003, 2015.

26. Liu Y, Yang B, Zhang L, Cong X, Liu Z, Hu Y, Zhang J and Hu H: Ginkgolic acid induces interplay between apoptosis and autophagy regulated by ROS generation in colon cancer. Biochem Biophys Res Commun 498: 246-253, 2018.

27. Zhou CC, Du W, Wen Z, Li JY and Zhang P: Effects of natural plant ginkgolic acids on the apoptosis of human Hep-2 cancer cells. Sichuan Da Xue Xue Bao Yi Xue Ban 40: 459-461, 2009 (In Chinese).

28. Yuan H, Ma Q, Cui H, Liu G, Zhao X, Li W and Piao G: How can synergism of traditional medicines benefit from network pharmacology? Molecules 22: E1135, 2017. 
29. Stelzl U, Worm U, Lalowski M, Haenig C, Brembeck FH, Goehler H, Stroedicke M, Zenkner M, Schoenherr A, Koeppen S, et al: A human protein-protein interaction network: A resource for annotating the proteome. Cell 122: 957-968, 2005.

30. Boezio B, Audouze K, Ducrot P and Taboureau O: Network-based approaches in pharmacology. Mol Inform 36, 2017.

31. Harris RC, Chung E and Coffey RJ: EGF receptor ligands. Exp Cell Res 284: 2-13, 2003

32. Freed DM, Bessman NJ, Kiyatkin A, Salazar-Cavazos E, Byrne PO Moore JO, Valley CC, Ferguson KM, Leahy DJ, Lidke DS and Lemmon MA: EGFR ligands differentially stabilize receptor dimers to specify signaling kinetics. Cell 171: 683-695.e18, 2017.

33. Sigismund S, Avanzato D and Lanzetti L: Emerging functions of the EGFR in cancer. Mol Oncol 12: 3-20, 2018.

34. Wang Z: ErbB receptors and cancer. Methods Mol Biol 1652 . 3-35, 2017.

35. Liu Q, Yu S, Zhao W, Qin S, Chu Q and Wu K: EGFR-TKIs resistance via EGFR-independent signaling pathways. Mol Cancer 17: 53, 2018

36. Cosmai L, Gallieni M and Porta C: Renal toxicity of anticancer agents targeting HER2 and EGFR. J Nephrol 28: 647-657, 2015.

37. Liu F, Shangli $Z$ and Hu Z: CAV2 promotes the growth of renal cell carcinoma through the EGFR/PI3K/Akt pathway. Onco Targets Ther 11: 6209-6216, 2018.
38. Liu L, Miao L, Liu Y, Qi A, Xie P, Chen J and Zhu H: S100A11 regulates renal carcinoma cell proliferation, invasion, and migration via the EGFR/Akt signaling pathway and E-cadherin. Tumour Biol 39: 1010428317705337, 2017.

39. Feng ZH, Fang Y, Zhao LY, Lu J, Wang YQ, Chen ZH, Huang Y, Wei JH, Liang YP, Cen JJ, et al: RIN1 promotes renal cell carcinoma malignancy by activating EGFR signaling through Rab25. Cancer Sci 108: 1620-1627, 2017.

40. Chen F, Deng J, Liu X, Li W and Zheng J: HCRP-1 regulates cell migration and invasion via EGFR-ERK mediated up-regulation of MMP-2 with prognostic significance in human renal cell carcinoma. Sci Rep 5: 13470, 2015.

41. Liang L, Li L, Zeng J, Gao Y, Chen YL, Wang ZQ, Wang XY, Chang LS and He D: Inhibitory effect of silibinin on EGFR signal-induced renal cell carcinoma progression via suppression of the EGFR/MMP-9 signaling pathway. Oncol Rep 28: 999-1005, 2012.

This work is licensed under a Creative Commons Attribution-NonCommercial-NoDerivatives 4.0 International (CC BY-NC-ND 4.0) License. 